\title{
Da virose biológica à virose econômica: uma vacina para microempresas no Brasil
}

\author{
Mauro Oddo Nogueira 1 \\ Sandro Pereira Silva 1 \\ Sandro Sacchet de Carvalho 1 \\ 1 Instituto de Pesquisa Econômica Aplicada, Rio de Janeiro / RJ - Brasil
}

\begin{abstract}
Diante da ameaça de desestruturação do tecido produtivo como consequência do isolamento social imposto no Brasil, e tendo em vista que as micro e pequenas empresas são aquelas mais duramente atingidas, o presente trabalho tem por objetivo formular uma proposta de auxílio emergencial governamental para este segmento econômico. Para tanto, apresenta uma breve análise das medidas já adotadas pelo Governo Federal, propõe uma medida capaz de preencher suas lacunas e, por fim, estima os custos da medida proposta para o Tesouro Nacional.
\end{abstract}

Palavras-chave: COVID-19; micro e pequenas empresas; políticas públicas; auxílio emergencial.

\section{De la virosis biológica a la virosis económica: una vacuna para microempresas en Brasil}

Ante la amenaza de desestructuración del tejido productivo como consecuencia del aislamiento social impuesto en Brasil y considerando que las micro y pequeñas empresas son las más afectadas, el presente trabajo tiene como objetivo formular una propuesta de asistencia gubernamental de emergencia a este segmento económico. Para ello, presenta un breve análisis de las medidas ya adoptadas por el Gobierno Federal, propone una medida capaz de llenar sus lagunas y, finalmente, estima los costos de la medida propuesta para el Tesoro Nacional.

Palabras clave: COVID-19; micro y pequeñas empresas; políticas públicas; ayuda del gobierno.

\section{From biological viruses to economic viruses: a vaccine for microenterprises in Brazil}

Facing the threat of disruption to the productive sector as a result of social distancing measures imposed in Brazil, and considering that micro and small enterprises are those hardest struck, this study aims to formulate a government emergency aid proposal for this segment. It presents a brief analysis of the federal government's current actions and proposes a measure capable of filling the gaps observed. Finally, the study offers an estimation of costs for the National Treasury if adopting the proposed measure.

Keywords: COVID-19; micro and small enterprises; public policy; government aid. 


\section{INTRODUÇÃO}

Muitas dúvidas e muito debate ainda giram em torno das medidas que os governos nacionais devem tomar para minimizar os evidentes impactos econômicos da pandemia produzida pelo coronavírus SARS-CoV-2. Há, contudo, algumas questões que parecem ter um razoável grau de consenso entre os analistas econômicos.

A primeira delas é que, independentemente da duração da crise e do grau de isolamento social imposto, os efeitos deletérios sobre a economia terão uma magnitude, ao menos, comparável à que caracterizou as maiores crises econômicas do mundo moderno. A virose biológica está produzindo seu "duplo", uma "virose econômica" transmissível por contágio, similarmente, de forma exponencial. As atividades econômicas ao redor do mundo estão sendo massivamente suspensas, seja por imposição do isolamento social, seja pela indisponibilidade de elevados contingentes de trabalhadores, resultado do recolhimento voluntário ou imposto pelo poder público. Como as empresas são elos das cadeias produtivas, a paralisação propaga-se a montante e à jusante, tanto pela suspensão das compras quanto pelo desabastecimento das empresas clientes. O resultado é a propagação rápida e grave de uma crise econômica desestruturante, ou mesmo, destruidora de cadeias produtivas ao redor de todo o globo.

A segunda, como decorrência do anterior, são as projeções cada vez mais incertas de evolução do PIB nos próximos meses, e o maior o grau da recessão esperada, conforme a duração e a profundidade da crise, podendo variar entre $-3,1 \%$ a $-11,0 \%$, de acordo com a consideração de cenários mais ou menos pessimistas (Dweck et al., 2020). Assim, a ausência de alguma forma massiva de socorro do Estado às empresas atingidas poderá transformar a crise em uma catástrofe socioeconômica sem precedentes na História.

A terceira é relativa ao "grupo de risco" mais sensível do universo empresarial, aquele formado pelas micro e pequenas empresas (MPEs), com limitado capital de giro e baixíssimas reservas de capital (Bartik et al., 2020). A grande maioria atua nos setores de comércio e serviços (Instituto Brasileiro de Geografia e Estatística [IBGE], 2020a, 2020b), justamente os mais atingidos. Os pequenos negócios no Brasil, sejam eles formais ou informais, ocupam quase $3 / 4$ da massa de trabalhadores (Nogueira \& Zucoloto, 2019). Portanto as consequências sociais decorrentes de um surto de desemprego, da suspensão dos salários ou da cessação de receitas individuais impactarão mais profundamente a maioria da sociedade brasileira. Sendo assim, as MPEs devem ser os principais agentes produtivos beneficiários das medidas de auxílio governamental.

Por fim, independentemente da forma de socorro estatal implementada, há certo consenso de que o fator tempo seja crucial para que a reação em cadeia não se torne incontrolável no âmbito da economia nacional. Pesquisa recente sobre a situação das MPEs brasileiras no contexto da COVID-19 aponta que sua capacidade de sobrevivência sem faturamento é, em média, de apenas 23 dias (Serviço Brasileiro de Apoio às Micro e Pequenas Empresas [Sebrae], 2020a).

Neste contexto, o objetivo do presente trabalho é propor um programa emergencial que contemple, de algum modo, os quatro pontos elencados e seja capaz de socorrer o segmento vulnerável das MPEs, visando preservar as cadeias produtivas e assegurar um rápido retorno à normalidade econômica após superado o episódio recessivo. Ao mesmo tempo, a proposta lançada minimizaria os impactos sociais e evitaria os riscos de uma convulsão diante do aprofundamento da crise. 


\section{PRIMEIRAS MEDIDAS GOVERNAMENTAIS ${ }^{1}$}

Desde a chegada da COVID-19 ao solo brasileiro, algumas medidas visando aliviar seus efeitos socioeconômicos sobre empresas e indivíduos foram adotadas pelo Governo Federal. Dentre o conjunto de ações destinadas à preservação das condições de operação e dos postos de trabalho nos pequenos negócios, três merecem destaque em virtude da expectativa de seus impactos: a Resolução $\mathrm{n}^{\circ} 850$ do Conselho Deliberativo do Fundo de Amparo ao Trabalhador (Codefat), de 18 de março de 2020 (Codefat, 2020); a Medida Provisória (MP) no 936, de $1^{\circ}$ de abril (2020) e a MP no 944, de 03 de abril (2020). O Quadro 1 contém uma síntese de cada uma delas.

\section{QUADRO 1 DESCRIÇÃO DAS MEDIDAS ANUNCIADAS}

\begin{tabular}{|c|c|}
\hline edidas & ão \\
\hline $\begin{array}{l}\text { Resolução } \\
\text { Codefat no } \\
850 / 2020\end{array}$ & $\begin{array}{l}\text { "Institui linha de crédito denominada Proger Urbano Capital de Giro, no âmbito do Programa de Geração } \\
\text { de Emprego e Renda (Proger), voltada para o financiamento de capital de giro isolado para empresas com } \\
\text { faturamento de até R\$ } 10 \text { milhões". A Resolução estabelece que ao menos } 60 \% \text { do total de operações devem } \\
\text { ser formalizadas para as MPEs enquadradas, assim definidas conforme Estatuto Nacional da Microempresa } \\
\text { e da Empresa de Pequeno Porte (Lei Complementar n } 123 / 2006) \text {. Os empréstimos são limitados a um } \\
\text { valor de } R \$ 500 \text { mil, com prazo de financiamento de até } 48 \text { meses, incluindo } 12 \text { meses de carência. Sobre } \\
\text { o empréstimo incidirá a Taxa de Longo Prazo (TLP), "[...] acrescida de taxa efetiva de juros de até } 12 \% \text { ao } \\
\text { ano" (art. } 3^{\circ} \text {, inciso VIII). }\end{array}$ \\
\hline $\begin{array}{l}M P n^{\circ} 936 \\
(2020)\end{array}$ & $\begin{array}{l}\text { Institui o Programa Emergencial de Manutenção do Emprego e da Renda (BEm). Em linhas gerais, esta } \\
\text { Medida Provisória (MP) permite a redução da jornada de trabalho, com redução proporcional do salário (em } \\
25 \%, 50 \% \text { ou } 70 \% \text { ); ou a suspensão temporária do contrato de trabalho. } 0 \text { prazo máximo para a redução } \\
\text { da jornada é de noventa dias e, para a suspensão do contrato, de sessenta dias (podendo ser fracionado em } \\
\text { dois períodos de trinta). Nas situações em que ambas as condições forem adotadas sucessivamente, o limite } \\
\text { total é de noventa dias. Em ambos os casos, os rendimentos dos trabalhadores serão complementados pelo } \\
\text { BEm, tendo como "base de cálculo o valor mensal do seguro-desemprego a que o empregado teria direito" } \\
\text { (art. } 6^{\circ} \text { e e serão integralmente custeados por recursos da União. }\end{array}$ \\
\hline $\begin{array}{l}M P n^{\circ} 944 \\
\text { (2020) }\end{array}$ & $\begin{array}{l}\text { Institui o Programa Emergencial de Suporte a Empregos. Trata-se de uma linha de crédito que define como } \\
\text { alvo as empresas com receita bruta anual superior a R } \$ 360 \text { mil e igual ou inferior a R } \$ 10 \text { milhões no } \\
\text { exercício de 2019. } 0 \text { empréstimo destina-se exclusivamente à cobertura de um máximo de dois meses } \\
\text { da folha de pagamentos da empresa e está limitado a um teto de dois salários mínimos por empregado. } \\
\text { Sobre o empréstimo incidirá uma taxa de juros de } 3,75 \% \text { a.a. (equivalente à taxa Selic em vigor na data } \\
\text { da publicação da Medida Provisória [MP]), com carência de seis meses e prazo de amortização de até } 36 \\
\text { meses, podendo ser operacionalizado por qualquer instituição financeira sujeita à supervisão do Banco } \\
\text { Central (Bacen). Como contrapartida, as empresas assumem o compromisso de garantia do emprego de } \\
\text { todos os seus trabalhadores por um período "compreendido entre a data da contratação da linha de crédito } \\
\text { e o sexagésimo dia após o recebimento da última parcela da linha de crédito" (art. } 2^{\circ} \text { ). }\end{array}$ \\
\hline
\end{tabular}

Fonte: Elaborado pelos autores.

\footnotetext{
${ }^{1}$ Para uma discussão mais aprofundada sobre tema, ver Nogueira, Silva, e Carvalho (2020).
} 
Uma análise ainda que preliminar dessas medidas já aponta algumas lacunas importantes em termos de cobertura dos riscos socioeconômicos elencados anteriormente. Primeiro, as ações podem ser consideradas ainda tímidas em relação a medidas tomadas por governos de outros países, que visam, em geral, aliviar o fluxo de caixa das empresas (especialmente as pequenas e médias), garantir um patamar de renda às famílias, manter vínculos empregatícios e reforçar a estrutura dos sistemas de saúde. Já existe um acervo considerável de estudos sobre as principais propostas internacionais que vêm sendo tomadas de forma emergencial, apontando estímulos previstos em relação ao PIB para apoiar as economias nacionais entre 6,3\% nos Estados Unidos e 17\% na Inglaterra e Espanha (Amitrano, Magalhães, \& Silva, 2020; Departamento Intersindical de Estatísticas e Estudos Socioeconômicos [Dieese], 2020; Fundação Getulio Vargas [FGV], 2020; Palludeto, Silva, Araujo, Borghi, \& Alves, 2020).

No caso brasileiro, as medidas anunciadas pelo Ministério da Economia, até o momento da elaboração deste texto, possuem custo de natureza fiscal estimado pouco superior a $2 \%$ do PIB (FGV, 2020), o que denota uma expressiva diferença em relação às atitudes internacionais. Ademais, as ações são de caráter difuso, sem uma coordenação federativa e intersetorial bem desenhada (Palludeto et al., 2020).

Do ponto de vista das MPEs, as condições de financiamento propostas pelos programas de crédito anunciados, dada a situação atual de extrema incerteza em relação às perspectivas de sustentabilidade de seus negócios, são, a princípio, pouco atraentes. Primeiro porque endividar-se na atual conjuntura é assumir um elevado patamar de risco. Segundo, como o risco creditício das operações recai sobre as instituições financeiras operadoras, a avaliação tenderá a ser rigorosa, tornando o instrumento inacessível a boa parte do segmento visado, o qual, mesmo em situações de normalidade, encontra dificuldade para acessar créditos. Como resultado, já existem indícios de "empoçamento" desses recursos, como demonstra pesquisa realizada pelo Sebrae, a qual registra que 59,2\% dos empresários entrevistados que tentaram acessar o instrumento tiveram o crédito negado (Sebrae, 2020a).

Destaca-se ainda o fato de a MP 944 (2020) não contemplar as microempresas com faturamento bruto anual de até R\$360 mil, que representam um contingente de quase 6,6 milhões de unidades, responsáveis por cerca de 15 milhões de empregos formais no país, ou seja, perto de $30 \%$ do total (Sebrae, 2020b). Em relação à destinação dos recursos, o fato de cobrir apenas as despesas com pessoal e, em muitos casos, nem mesmo a sua totalidade, não garante a preservação do capital de giro mínimo necessário para a sobrevivência de um empreendimento parado, uma vez que os custos fixos continuam incidindo sobre as empresas. Nestas condições, o empresário vê-se diante do dilema de decidir entre correr o risco de fechar seu estabelecimento e demitir funcionários ou assumir uma dívida cujo montante não é suficiente para cobrir suas despesas remanescentes. Outro aspecto a ser observado é que sobre o financiamento incide a taxa Selic. Isso significa que, descontada a inflação (que já vinha em trajetória de queda), o custo fiscal efetivo para a União é nulo, posto que essa taxa corresponde ao custo de oportunidade do dinheiro para o Tesouro Nacional (TN).

No tocante à MP 936/2020, há pelo menos duas questões a serem consideradas. Primeiramente, o mecanismo de complementação da renda desses trabalhadores ao tomar o valor do seguro-desemprego como base de cálculo do complemento implica, na prática, a redução da massa salarial, uma vez que limita o benefício a $\mathrm{R} \$ 1.813,03$. Segundo, ao assumir o compromisso de garantia do emprego os empresários que não lograrem a sobrevivência de seus negócios serão forçados a arcar com as indenizações relativas a esse dispositivo.

Por fim, vale ressaltar que o governo federal sancionou a Lei $\mathrm{n}^{\circ}$ 13.999, de 18 de maio de 2020, que instituiu o Programa Nacional de Apoio às Microempresas e Empresas de Pequeno Porte 
(Pronampe). O programa estabelece a criação de uma linha de crédito especial para MPEs de valor correspondente a até $30 \%$ de sua receita bruta do ano de 2019, com 36 meses para o pagamento. Contudo, o Pronampe, da forma como foi sancionado, mantém alguns aspectos que tendem a dificultar o socorro pretendido às MPEs, dado o contexto de incertezas que se desdobra nesta crise. Entre eles, podemos citar: a restrição de assunção do risco por parte do governo de $85 \%$ dos empréstimos, o restante do risco fica a cargo dos bancos; o veto presidencial ao tempo de carência para o pagamento dos empréstimos, previsto originariamente no projeto de lei; e a cobrança de uma taxa de juros igual à taxa Selic acrescida de 1,25\%. Nessa perspectiva, o papel do Estado como garantidor da viabilização do programa é bastante frágil, pois, por um lado, o fato de dividir o risco com os bancos leva a que as exigências para aprovação dos créditos sejam mantidas, e, por outro, tanto a revogação de carência no pagamento quanto a definição de taxa de juros positiva inibem o acesso ao programa por parte importante das MPEs, dado o cenário de incertezas quanto à recuperação de suas receitas.

\section{PROPOSIÇÕES}

Em virtude da conjuntura atual descrita, entendemos que uma reação por parte do governo federal, implementada de maneira rápida e abrangente, poderia auxiliar tanto na mitigação dos impactos socioeconômicos da pandemia em curto prazo, quanto na preservação das bases para a retomada das atividades no período pós-crise.

Relativamente ao apoio às MPEs, de modo a possibilitar que elas ultrapassem a crise resguardando seus postos de trabalho e conservando as cadeias produtivas, sugerimos o seguinte desenho programático:

i) Concessão de empréstimo proporcional ao faturamento para a preservação do capital de giro a todas as MPEs do país (com faturamento bruto anual de até $\mathrm{R} \$ 4,8$ milhões), com juros nominais iguais a zero. A concessão deve ser condicionada à manutenção dos empregos por um período equivalente a seis meses após o encerramento do isolamento social. A amortização do empréstimo deverá se dar por prestações constantes, com um ano de carência a partir da suspensão do isolamento social, em um prazo equivalente a um ano para cada mês de utilização do crédito, podendo ser oferecido algum incentivo para a antecipação da quitação do crédito;

ii) A operacionalização deste crédito deve ser aberta a todas as instituições financeiras, incluindo bancos públicos e privados, fintechs, cooperativas de crédito e correspondentes bancários (Correios e agências lotéricas). Estes agentes poderão ser remunerados a uma taxa de até 1,5\% dos valores nominais concedidos. A análise de risco deve ser simplificada e a inadimplência garantida pelo TN, minimizando, assim, as negativas de concessão de crédito;

iii) O valor máximo do crédito a ser concedido deve ser proporcional ao faturamento médio mensal - de acordo com a atividade da empresa.

Para melhor detalhamento, ressalta-se o fato de que o isolamento social imposto em função da epidemia da COVID-19 impacta de forma distinta cada uma das atividades econômicas. Dois estudos recentes auxiliam na determinação do grau de impacto e da vulnerabilidade das diversas atividades à crise. Baseados no contingente de empregados, no coeficiente locacional, no número de empregados com mais de 60 anos de idade e no contingente de empresas de menor porte (menos de 50 empregados), Rauen, Paiva, Leão, e Furtado (2020) construíram um ranking da sensibilidade 
das atividades econômicas aos impactos da COVID-19, indicando as condições de operação durante o confinamento para as 20 mais sensíveis. Já no estudo produzido pelo Sebrae (2020a), por meio um survey com 6.080 micro e pequenos empresários, para colher sua percepção a respeito dos impactos da pandemia sobre seus negócios, foram considerados 15 segmentos empresariais potencialmente mais sensíveis (positiva ou negativamente) aos efeitos da crise.

Combinando os resultados dos dois estudos com outras informações disponíveis sobre as atividades que estão paralisadas, foi possível elaborar um rol dos segmentos de negócios negativa e significativamente afetados (Quadro 2). Para que as empresas sejam capazes de manter suas atividades e os empregos, consideramos que os empréstimos concedidos nas condições acima deverão cobrir: o valor da massa salarial, metade do consumo intermediário (estimativa que leva em conta que os custos variáveis deixaram de ocorrer) e mais $10 \%$ de margem, a fim de cobrir as eventuais especificidades (os cálculos foram feitos com base nos valores agregados e médias dos segmentos), e também alguma remuneração para seus proprietários. ${ }^{2}$ Estes são, portanto, os percentuais máximos do faturamento médio mensal de cada empresa que o montante do empréstimo mensal pode atingir.

Por fim, tendo em vista que os demais segmentos também são indiretamente atingidos, uma vez que a atividade econômica do país se reduziu como um todo, consideramos necessário disponibilizar também o crédito, em um valor reduzido, para as demais MPEs que não se enquadrem nos segmentos considerados. No quadro 2, estas empresas estão agregadas no segmento "Não Priorizados”.

\section{QUADRO 2 SEGMENTOS ATENDIDOS PELO EMPRÉSTIMO COM RESPECTIVOS VALORES}

\begin{tabular}{lccc}
\hline \multicolumn{1}{c}{ Segmento } & Total de MPEs & \% Fat. & $\begin{array}{c}\text { Valor Médio } \\
\text { Empréstimo (R\$) }\end{array}$ \\
\hline Artesanato & 16.222 & 60 & $61.946,45$ \\
Beleza / Serviços pessoais & 46.812 & 60 & $12.949,92$ \\
Construção Civil & 165.100 & 55 & $30.641,30$ \\
Economia criativa (eventos e produções) & 20.074 & 45 & $9.484,47$ \\
Moda & 406.714 & 60 & $21.251,91$ \\
Oficinas e peças automotivas & 188.381 & 60 & $19.224,69$ \\
Serviços de alimentação & 210.653 & 60 & $20.718,06$ \\
Serviços educacionais & 54.188 & 55 & $13.992,28$ \\
Turismo & 70.574 & 60 & $21.348,19$ \\
Varejo & 371.821 & 60 & $22.702,01$ \\
Outros & 677.578 & 50 & $17.207,27$ \\
Não Priorizados & 934.565 & 20 & $9.949,09$ \\
Total & 3.162 .682 & - & $17.438,67$ \\
\hline
\end{tabular}

Fonte: Elaborada pelos autores baseado em Rauen et al. (2020), Sebrae (2020a) e IBGE (2020a).

\footnotetext{
${ }^{2} \mathrm{~A}$ fim de estabelecer o percentual do faturamento para base de cálculo do empréstimo, utilizamos uma tabulação especial dos dados das pesquisas setoriais (IBGE, 2020a) realizada pelo IBGE. No recorte por porte nela realizado, foi utilizado o critério de faturamento que passou a vigorar a partir de 2018. Dada a crise econômica que prevaleceu no período 2018/2019, é improvável que o faturamento médio das empresas tenha crescido significativamente. Portanto é lícito supor que este critério de recorte representa a realidade atual. Uma vez que os dados referem-se ao ano de 2017, tanto para o procedimento aqui descrito, quanto para as estimativas de custos do programa sugerido, foi necessário que se inflacionassem os valores monetários. Para a massa salarial, foi adotado o INPC, parâmetro utilizado para o reajuste anual do salário mínimo nacional. Para os valores relativos ao faturamento e às aquisições, adotou-se o IPCA, índice que reflete o comportamento destes preços. Os valores dos percentuais obtidos foram arredondados para unidades múltiplas de cinco.
} 
Considerando-se que o programa aqui proposto seja, em princípio, capaz de assegurar a manutenção das MPEs do país, mesmo com suas atividades temporariamente paralisadas, entendemos que ele possibilitaria substituir a maior parte do complexo rol de medidas voltadas para este segmento até a presente data.

\section{CUSTOS PARA O TESOURO NACIONAL E RESPECTIVOS FINANCIAMENTOS}

Dada a imprevisibilidade de duração do isolamento, construímos quatro cenários, considerando um lapso temporal de dois a cinco meses.

Pelo Quadro2, as pesquisas setoriais do IBGE estimam um total de 3,163 milhões de MPEs nas atividades pesquisadas (IBGE, 2020a). Entretanto, segundo o Sebrae (2020b), com base em dados da Receita Federal (RFB), o total de MPEs no Brasil é de 7,750 milhões. Alguns fatores explicam tal divergência. Do lado das pesquisas setoriais, em primeiro lugar, nem todas as atividades econômicas estão incluídas. Em segundo lugar, o desenho amostral pode resultar em uma subestimação do total de empresas. Além do que, os dados do IBGE referem-se ao ano de 2017, podendo estar defasados em virtude do surgimento posterior de novas MPEs. Quanto aos dados do Sebrae, por se tratar dos registros administrativos da Receita Federal, presume-se que representem uma realidade mais fidedigna. Todavia eles incluem também empresas inativas, de modo que podem implicar superestimação no nosso cálculo dos custos, o que representaria uma postura conservadora de abordagem. Por tais divergências, optamos por "ajustar" os valores obtidos nas pesquisas setoriais do IBGE pela razão entre as quantidades de empresas das duas fontes de dados $(2,45)$, assumindo uma provável superestimação. Os valores previstos para o desembolso do TN em cada cenário estão apresentados no quadro 3.

QUADRO 3 DESEMBOLSO DO TESOURO NACIONAL PARA CADA CENÁRIO (R\$ BILHÃO)

\begin{tabular}{lccccc}
\hline Componente do & \multirow{2}{*}{$\begin{array}{c}\text { Desembolso } \\
\text { Mensal }\end{array}$} & \multicolumn{5}{c}{ № de meses de duração do programa } \\
\cline { 2 - 6 } & $\mathbf{2}$ & $\mathbf{3}$ & $\mathbf{4}$ & $\mathbf{5}$ \\
\hline Auxílio & 135,1 & 270,3 & 405,4 & 540,6 & 675,7 \\
Taxa Adm. & 2,1 & 4,1 & 6,1 & 8,1 & 10,1 \\
Total & $\mathbf{1 3 7 , 2}$ & $\mathbf{2 7 4 , 4}$ & $\mathbf{4 1 1 , 5}$ & $\mathbf{5 4 8 , 7}$ & $\mathbf{6 8 5 , 8}$ \\
$\%$ DPF & 3,20 & 6,41 & 9,61 & 12,82 & 16,02 \\
\hline
\end{tabular}

Fonte: Elaborada pelos autores baseado em IBGE (2020a), Sebrae, (2020b) e ME (2020).

Considerando que o montante emprestado a cada mês é da ordem de $\mathrm{R} \$ 135,1$ bilhões e que seriam até 7,750 milhões de empresas atendidas, tem-se, como valor médio mensal do empréstimo, $\mathrm{R} \$ 17.438,67$. Como os juros propostos são iguais a zero, a prestação média para a amortização deverá ser de $\mathrm{R} \$ 1.607,10$.

É fundamental que se observe que os valores do Quadro 3 referem-se tão somente a desembolso e não ao seu custo efetivo. Como se trata de um empréstimo, o TN estaria fazendo apenas uma antecipação, recuperada pelo valor nominal do título com a amortização dos financiamentos. Portanto, tendo em vista que a proposta considera o empréstimo com juros iguais a zero, o custo dele

ReVista de administração PÚblica | Rio de Janeiro 54(4):1010-1021, jul. - ago. 2020 
corresponderia ao custo de oportunidade (taxa Selic, atualmente fixada em 3,0\% a.a.) do montante concedido, capitalizado no prazo de um ano de carência, o prazo de amortização. O quadro 4 apresenta os resultados desta capitalização.

É importante destacar que estes valores consideram a hipótese de que todas as empresas qualificáveis para o programa irão fazer uso dele, o que não deve corresponder à realidade, especialmente no caso daquelas que atuam nas atividades classificadas como "Não Priorizados". Isto significa que o desembolso concreto - e, consequentemente, o custo - deverá ser menor do que o previsto.

Os valores apresentados estão em valores presentes, isto é, não levam em conta a inflação, que implicará um aumento dos custos. Contudo, a inflação já vem apresentando um viés de baixa. Em face da contração esperada da demanda, é provável que esse viés intensifique-se, ao menos no médio prazo.

QUADRO 4 CUSTO EFETIVO PARA O TESOURO NACIONAL PARA CADA CENÁRIO (EM R\$ BILHÃO)

\begin{tabular}{lcccc}
\hline \multirow{2}{*}{ Custo } & \multicolumn{4}{c}{ № de meses de duração do programa } \\
\cline { 2 - 5 } & $\mathbf{2}$ & $\mathbf{3}$ & $\mathbf{4}$ & $\mathbf{5}$ \\
\hline Anual & 8,6 & 10,9 & 13,2 & 15,5 \\
Global & 17,1 & 32,6 & 52,7 & 77,6 \\
Adm. & 4,1 & 6,1 & 8,1 & 10,1 \\
Total & $\mathbf{2 1 , 2}$ & $\mathbf{3 8 , 7}$ & $\mathbf{6 0 , 8}$ & $\mathbf{8 7 , 7}$ \\
\% PIB 2019 & 0,29 & 0,53 & 0,84 & $\mathbf{1 , 2 1}$ \\
\hline
\end{tabular}

Fonte: Elaborada pelos autores baseado em IBGE (2020a), Sebrae (2020b) e Ipeadata (2020).

O financiamento presente dos desembolsos pode ser feito por intermédio da emissão de títulos públicos, posto que eles serão resgatados nas datas das amortizações dos empréstimos. Neste caso, conforme apresentado no Quadro3, para cada mês de duração do programa haveria um acréscimo de 3,20\% no estoque da Dívida Pública Federal (DPF). Tais impactos se limitariam aos custos efetivos do programa, e na época do resgate dos títulos podem ser avaliadas as melhores formas de financiá-los.

\section{CONSIDERAÇ̃̃ES FINAIS}

Este estudo apresentou a formulação de um programa emergencial para a mitigação dos impactos socioeconômicos da pandemia da COVID-19 no Brasil, em virtude do esgarçamento de seu tecido produtivo e seus desdobramentos em termos de ameaça sobre o conjunto das MPEs, que representam aproximadamente $75 \%$ dos postos de trabalho existentes no país.

Os custos das medidas propostas para o TN, pelo exposto, estão superestimados, o que denota uma perspectiva mais conservadora de avaliação dos riscos fiscais, adequada para um momento de incertezas como o atual. Além disso, seu efeito multiplicador seria um contraponto a uma esperada e representativa queda da arrecadação futura dos governos federal e subnacionais, decorrente da retração da atividade econômica resultante da crise. 
RAP | Da virose biológica à virose econômica: uma vacina para microempresas no Brasil

Por fim, vale ressaltar que o fenômeno atualmente vivenciado é inédito, dada a dinâmica geradora da crise econômica. Não se trata de ter pela frente um cenário de elevados riscos, mas, sim, de absoluta incerteza. Neste contexto, entendemos que não há outra alternativa senão o Estado assumir os ônus relativos às ações necessárias para a sustentação da sociedade como um todo, socorrendo os segmentos mais seriamente ameaçados para que o país consiga preservar uma parcela significativa do seu tecido produtivo, fundamental ao processo de retomada da economia. 


\section{REFERÊNCIAS}

Amitrano, C., Magalhães, L. C. G., \& Silva, M. S. (2020). Medidas de enfrentamento dos efeitos econômicos da pandemia Covid-19 (Texto para Discussão, n. 2559). Brasília, DF: Ipea.

Bartik, A., Bertrand, M., Cullen, Z. B., Glaeser, E., Luca, M., \& Stanton, C. T. (2020, April). How are small businesses adjusting to COVID-19? Early evidence from a Survey (Working Paper n. 26989). National Bureau of Economic Research [NBER] Working Paper Series, Cambridge. Recuperado de https://www.nber.org/papers/w26989.pdf

Conselho Deliberativo do Fundo de Amparo ao Trabalhador. (2020). Resolução Codefat $n^{\circ}$ 850, 18 de março de 2020. Brasília, DF: Codefat.

Departamento Intersindical de Estatísticas e Estudos Socioeconômicos. (2020). Medidas adotadas por vários países para conter os efeitos econômicos da pandemia do coronavírus. (Nota Técnica no 224). São Paulo, SP: Dieese.

Dweck, E., Rocha, C. F, Freitas, F, Ferraz, J. C., Torracca, J., Costa, K. V., ... Miguez, T. (2020, maio). Impactos macroeconômicos e setoriais da Covid-19 no Brasil (Nota Técnica). Rio de Janeiro, RJ: UFRJ. Recuperado de https://www.ie.ufrj.br/images/IE/ grupos/GIC/GIC_IE_NT_ImpactosMacroSetoriai sdaC19noBrasilvfinal22-05-2020.pdf

Fundação Getulio Vargas. (2020). As políticas que estão sendo adotadas para o combate ao Covid-19: experiência internacional e o Brasil. São Paulo, SP: Autor. Recuperado de https://is.gd/LNci4o

Instituto Brasileiro de Geografia e Estatística. (2020a). Pesquisa Industrial Anual 2017; Pesquisa Anual da Construção 2017; Pesquisa Anual de Serviços 2017 e Pesquisa Anual de Comércio 2017. Rio de Janeiro, RJ: IBGE.

Instituto Brasileiro de Geografia e Estatística. (2020b). Pesquisa Nacional por Amostra de Domicílios Contínua Trimestral: $1^{\circ}$ trimestre de 2020. Rio de Janeiro, RJ: IBGE.
Ipeadata. Produto Interno Bruto. (2020). Brasília, DF: Ipea. Recuperado de https://is.gd/L8rmpk

Medida Provisória $n^{\circ}$ 936, de $1^{\circ}$ de abril de 2020. (2020). Brasília, DF: Presidência da República.

Medida Provisória no 944, de 3 de abril de 2020. (2020). Brasília, DF: Presidência da República.

Ministério da Economia. (2020). Relatório Mensal da Dívida Pública Federal: fev. 2020. Brasília, DF: Tesouro Nacional. Recuperado de https://is.gd/ c443br

Nogueira, M. O., \& Zucoloto, G. F. (2019). Um pirilampo no porão: um pouco de luz nos dilemas da produtividade das empresas e da informalidade no Brasil (2a ed.). Brasília, DF: Ipea.

Nogueira, M. O., Silva, S. P., \& Carvalho, S. S. (2020). Socorro governamental às pequenas unidades produtivas frente à atual pandemia (Nota Técnica, ${ }^{\circ}$ 63). Brasília, DF: Ipea.

Palludeto, A.W., Silva, N. G., Araujo, R. F., Borghi, R. A., Z., \& Alves, V. L. S. (2020, 15 de maio). Política econômica em tempos de pandemia: experiências internacionais selecionadas (Série Laboratório de Economia Internacional, n. 01). Campinas, São Paulo: Unicamp. Recuperado de https://www.eco. unicamp.br/images/arquivos/LEI_01_2020_ceri.pdf

Rauen, A., Paiva, B., Leão, R., \& Furtado, B. (2020). Emprego setorial e o enfrentamento à Covid-19. (Boletim Radar, n. 62). Brasília, DF: Ipea.

Serviço Brasileiro de Apoio às Micro e Pequenas Empresas. (2020a). O Impacto da pandemia de corona vírus nos pequenos negócios (2a ed.). Brasília, DF: Autor. Recuperado de https://datasebrae.com. $\mathrm{br} / \mathrm{wp}$-content/uploads/2020/04/Impacto-docoronav\%C3\%ADrus-nas-MPE-2\%C2\%AAedicao_ geral-v4-1.pdf

Serviço Brasileiro de Apoio às Micro e Pequenas Empresas. (2020b). Painel de Empresas. Sebrae: Brasília, DF: Autor. Recuperado de https://is.gd/ ty $5 \mathrm{~A} 8 \mathrm{o}$ 
RAP | Da virose biológica à virose econômica: uma vacina para microempresas no Brasil

\section{Mauro Oddo Nogueira}

https://orcid.org/0000-0001-7509-0491

Doutor em Engenharia de Sistemas e Computação; Pesquisador do Instituto de Pesquisa Econômica Aplicada (Ipea).E-mail: mauro.oddo@ipea.gov.br

\section{Sandro Pereira Silva}

\section{https://orcid.org/0000-0002-8836-0128}

Doutor em Economia; Pesquisador do Instituto de Pesquisa Econômica Aplicada (Ipea).

E-mail: sandro.pereira@ipea.gov.br

\section{Sandro Sacchet de Carvalho}

https://orcid.org/0000-0001-5774-5685

Doutor em Economia; Pesquisador do Instituto de Pesquisa Econômica Aplicada (Ipea).

E-mail: sandro.carvalho@ipea.gov.br 
RAP | Da virose biológica à virose econômica: uma vacina para microempresas no Brasil

\section{APÊNDICE}

\section{QUADRO A GRUPOS (3 DÍGITOS) DA CNAE 2.0 POR SEGMENTO}

\begin{tabular}{|l|l|}
\hline \multicolumn{2}{|c|}{ Segmento } \\
\hline Artesanato & $22.1 / 22.2 / 23.1 / 32.9$ \\
\hline Beleza / Serviços pessoais & 96.0 \\
\hline Construção Civil & $16.2 / 42.2 / 23.3 / 42.9 / 23.4 / 43.1 / 23.9 / 43.2 / 41.1 / 43.3 / 41.2 / 43.9 / 42.1 / 77.3$ \\
\hline Economia criativa & $59.1 / 90.0$ \\
\hline Moda & $13.1 / 14.2 / 13.2 / 15.1 / 13.3 / 15.2 / 13.4 / 15.3 / 13.5 / 15.4 / 14.1 / 47.8$ \\
\hline Oficinas e peças automotivas & $45.2 / 45.3 / 45.4$ \\
\hline Serviços de alimentação & $56.1 / 56.2$ \\
\hline Serviços educacionais & $85.5 / 85.9$ \\
\hline Turismo & $49.5 / 77.1 / 50.9 / 79.1 / 51.1 / 79.9 / 55.1 / 82.3 / 55.9 / 93.2$ \\
\hline Varejo & $47.1 / 47.5 / 47.6$ \\
\hline Outros & $16.1 / 68.1 / 18.1 / 68.2 / 18.2 / 69.1 / 18.3 / 69.2 / 25.3 / 71.1 / 25.4 / 71.2 / 25.9 / 73.1 /$ \\
& $30.1 / 73.2 / 31.0 / 74.1 / 32.1 / 74.2 / 32.2 / 74.9 / 32.3 / 77.2 / 32.4 / 78.1 / 33.1 / 81.2 /$ \\
\hline
\end{tabular}

Fonte: Elaborado pelos autores. 